\title{
Propuesta metodológica de representación gráfica aplicada al estudio antropológico de la cultura cañari
}

GRAPHIC REPRESENTATION METHODOLOGICAL PROPOSAL APPLIED TO THE ANTHROPOLOGICAL STUDY OF THE CAÑARI CULTURE

Recibido: 15/06/2020

Aceptado: $15 / 07 / 2020$

\author{
Mónica Liliana Castro Pacheco이 Kléber John Lema Polo², Bruno Fernando Nievecela Avila ${ }^{3}$ \\ 1. * Docente del Instituto Tecnológico Sudamericano, Cuenca- Ecuador. Email: mocastro@sudamericano.edu.ec \\ ORCID: https://orcid.org/0000-0002-3850-0276 \\ 2. Docente del Instituto Tecnológico Sudamericano. Cuenca- Ecuador. Email: jlema@sudamericano.edu.ec \\ ORCID: https://orcid.org/0000-0002-7242-1125 \\ 3. Docente del Instituto Tecnológico Sudamericano, Cuenca- Ecuador Email: brunievecela@sudamericano.edu.ec \\ ORCID: https://orcid.org/0000-0002-8344-8868
}

\begin{abstract}
Para Citar: Castro Pacheco, M. L., Lema Polo, K. J., \& Nievecela Avila, B. F. (2020). Propuesta metodológica de representación gráfica aplicado al estudio antropológico de la cultura cañari. Revista Publicando, 7(25), 136-145. Recuperado a partir de https://revistapublicando.org/revista/index.php/crv/article/view/2097
\end{abstract}

\begin{abstract}
Resumen: Hoy en día existe una gran cantidad de productos que hacen referencia o rinden homenaje a diversas simbologías o gráficas referentes a culturas; a lo largo de la historia dichas representaciones eran generadas de forma autóctona por parte de artesanos en diversas áreas como son: textiles, cerámicas, decoración y demás productos con una carga simbólica en referencia a una cultura. Esto provoca un conflicto en el entendimiento de: formas, figuras o cromática, respecto al concepto y trasfondo del elemento, además el mal manejo contribuye al uso no apropiado de posteriores representaciones, esto debido a una ausencia de una metodología que aporte conceptos básicos de construcción de la imagen, semiótica y cromática.

Este artículo describe el manejo de elementos compositivos, mediante un uso acorde a metodologías referentes al diseño, para ello propone el desarrollo de un manual de representación de formas sígnicas de la Cañari. Esta publicación puede ser utilizada por docentes, estudiantes y profesionales del área del Diseño Gráfico, como un referente para la visualización de composiciones gráficas e ilustraciones que se obtuvieron del análisis de objetos precolombinos, aplicados en un artículo de uso diario como es una bolsa ecológica de compras a través del siguiente proceso: análisis morfológico, geometrización formal, uso de cromática, tipografía para la obtención de propuestas equilibradas y estéticas.
\end{abstract}

Palabras clave: Diseño, síntesis, línea, módulo, simetría.
Abstract: Today there is a large number of products that refer to or pay tribute to various symbols or graphics referring to cultures; throughout history these representations were generated in a native way by craftsmen in various areas such as: textiles, ceramics, decoration and other products with a symbolic load in reference to a culture. This causes a conflict in the understanding of: forms, figures or chromatics, with respect to the concept and background of the element, in addition the bad management contributes to the nonappropriate use of later representations, this due to an absence of a methodology that contributes basic concepts of construction of the image, semiotics and chromatics.

This article describes the handling of compositional elements, through a use according to methodologies related to the design, for this purpose it proposes the development of a manual for the representation of signical forms of the Cañari. This publication can be used by teachers, students and professionals in the area of Graphic Design, as a reference for the visualization of graphic compositions and illustrations that were obtained from the analysis of pre-Columbian objects, applied in an article of daily use such as an ecological shopping bag through the following process: morphological analysis, formal geometry, use of chromatics, typography to obtain balanced and aesthetic proposals.

Keywords: Design, synthesis, line, module, symmetry. 


\section{INTRODUCCIÓN}

$\mathrm{E}$ 1 diseño gráfico ha tenido gran importancia en la búsqueda de nuevos conceptos visuales a partir del estudio y tratamiento de las culturas aborígenes en América Latina. En los últimos años se ha buscado y considerado, de sobremanera, la preservación de sus raíces es por esto que se ha visto inmerso en diferentes intereses con múltiples posturas y perspectivas cambiar el pensamiento hegemónico y colonial que éstas han tenido.

La difusión del arte ha llevado al diseño a un nuevo nivel masificando contenidos; Jesús Martín-Barbero (2002) habla sobre un ecosistema comunicativo donde propone que las relaciones entre comunicación y cultura han beneficiado a su masificación. Por ello el exponer cada cultura a las otras, tanto del mismo país como del mundo entero, aceleran el intercambio y la interacción.

La tecnología brinda el acceso que antes podía excluir el conocerlas, además que favorece a la recreación y transformación de estas. "La comunicación cultural en la era de la información nombra ante todo la experimentación. Es decir, la experiencia de apropiación e invención" (MartínBarbero, 2001, p.34).

En la actualidad Ecuador se encuentra inmerso en la revolución tecnológica, el acceso a ella ha provisto de herramientas a muchos artistas, el crecimiento de dispositivos aumenta la asequibilidad para que muchos artistas y consumidores de contenido digital puedan difundir sus ideas. Como docentes en el área de Artes se ha apreciado que el diseño gráfico está jugando un rol muy importante como aporte al reconocimiento de lo que representa el ser ecuatoriano, no solo a nivel local sino a nivel mundial. De esta manera el presente análisis y desarrollo propuesto contribuye como una guía para el manejo de recursos gráficos proporcionados por una cultura del Ecuador como ejemplo, para ello se pretende usar como referente a la Cañari perteneciente a la Zona 6 del Ecuador (Basantes et al., 2017).

El presente artículo está basado en la investigación "Diseño de signos visuales mediante el análisis de formas sígnicas de la Cultura Cañari para la aplicación en productos ecológicos" el cual corresponde a un estudio realizado por parte de la Carrera de Diseño Gráfico y financiado por Instituto Superior Tecnológico Particular Sudamericano, el mismo consistió en la recopilación de datos obtenidos de una muestra de 500 personas de la ciudad de Cuenca, revelando detalles tan marcados como el desconocimiento de esta, sobre todo en la simbología representada en sus objetos.

Cabe destacar que dicho estudio recopiló información previa de las formas, signos, cromática y demás elementos que forman parte de esta comunidad precolombina; en donde luego de un análisis morfológico de sus aspectos más representativos $y$, con fundamentos propios de diseño, se obtuvo como resultado una propuesta logrando una reorganización de formas contemporáneas en donde los símbolos y signos se identifican de manera similar a las primitivas, las mismas que concluyen en una composición decorativa aplicable en un artículo de uso diario como es una bolsa ecológica de compras.

\section{METODOLOGÍA}

Este escrito está realizado mediante un enfoque de tipo cualitativo aplicando un diseño de campo a nivel descriptivo y explicativo por las diferentes fases para llegar a un resultado práctico, por ello se emplearon los datos e información recopiladas antes mencionadas.

Cabe destacar que el diseño, como disciplina, tiene su propia metodología, ya que a lo largo del tiempo existen diseñadores que han validado el proceso para encontrar su finalidad. Según Wucius Wong (2014), el diseño es un proceso de creación visual con un propósito, sin embargo, también puede ser partícipe de la metodología de investigación, en este caso de tipo explicativa con prototipado ya que se basa en la determinación de las causas y las consecuencias del uso correcto de los elementos representativos de una cultura, por ello se pretende determinar el qué y el porqué de cómo aplicar los elementos contenidos en el soporte gráfico de los artes a ser usados.

El proceso realizado partió de la idea de fusionar y entender las metodologías de investigación usando los principios del diseño, por lo que se pretende aportar en su alcance la forma de afrontar un proceso de análisis e interpretación en cuanto sus elementos inscritos en vestigios de culturas precolombinas y en la diversidad de formas de expresión inspirados en la naturaleza, rituales y tradiciones de esta. 
Dichas representaciones se resaltan por el uso de abstracciones con una marcada importancia tomando como énfasis elementos que a la vez se convirtieron en sus deidades, entre éstas se encuentran: la luna, el sol, la serpiente, la guacamaya, las montañas, la chacana, etc.; además de formas geométricas como: cuadrados, espirales, círculos entre otros.

Mediante los criterios y las herramientas del diseño gráfico se interpretan las características más significativas tomadas de dichos vestigios para el desarrollo de propuestas contemporáneas. Es importante destacar que el diseño debe partir, en su gran mayoría, de bases teóricas que sirvan de inspiración y con ello justificar el nacimiento de nuevas formas con elementos representativos, uno de estos es el manual del usuario en donde cada nuevo gráfico se elabora con fundamentos del diseño usando criterios de construcción que justifique las decisiones tomadas durante la elaboración.

\section{DESARROLLO}

El papel del diseñador es comunicar de forma directa, transformando ideas en nuevos conceptos usando herramientas con las cuales esta propuesta logre una solución visual agradable y exitosa, de esta forma se consigue la eficacia en la comunicación del mensaje siendo captado de manera positiva y atractiva.

Dado el estudio dentro del diseño gráfico, la semiología toma vital importancia en el estudio de los signos, según Umberto Eco (2000): "la semiótica estudia todos los procesos culturales como proceso de comunicación, y sin embargo cada uno de dichos procesos parece subsistir solo porque por debajo de ellos establece un sistema de significación" (p.24). La relación de comunicación entre cada signo en un determinado entorno expresa algo, siendo necesario poder entender su significado, sobre todo la coherencia que debe existir al momento de dar su correcto mensaje y que el receptor lo entienda sin errores.

Luego de realizar un estudio morfológico sobre los detalles que aportan la gráfica contenida en los diversos artículos cañaris analizados, se pudo observar que su iconografía resulta como consecuencia de una creencia, una divinidad o una cosmovisión; dentro de las más importantes se destacan:
- Iconografía zoomorfa: con énfasis en animales muy importantes dentro de su cultura, la realización de este tipo de elementos era de uso diario, en algunos casos los utilizaban en eventos ceremoniales o religiosos.

- Iconografía antropomorfa: con formas humanas, éstas eran con base en representaciones de sus dioses o sus gobernantes, este tipo de objetos varía según el uso y se hallan realizados en materiales como metal entre estos oro y plata, cerámica y en algunos casos realizados en piedra.

- Iconografía abstracta: estas formas son las más usadas y fueron destinadas a la decoración en general, se repiten en varios de los vestigios encontrados junto con la simetría y la repetición de figuras, haciendo que las mismas ofrezcan un gran punto de partida para la obtención de diseños siendo inspiración para varias propuestas.

- Iconografía fitomorfa: la naturaleza también fue parte de su expresión, aquí la representación se asemejaba a la flora del lugar.

Los elementos tomados en cuenta para esta investigación, dentro de la iconografía estudiada fueron:

Serpiente: constituye a la iconografía zoomorfa, considerado uno de los referentes de esta comunidad, ha estado presente en algunos aspectos a lo largo de la historia, la serpiente "padre serpiente". Era un animal muy respetado debido a que, según la leyenda, es el progenitor de esta raza, es un simbolismo que tiene mucha fuerza en la cosmovisión de la Cultura Cañari, es un animal sagrado considerado un dios (Garzón, 2012, p.40).

Guacamaya: Era considerada mensajera de los dioses, su iconografía es zoomorfa, también representa un símbolo que explica una nueva historia de este pueblo, para ellos las guacamayas fueron quienes salvaron la nación de una catástrofe universal "se fundamenta en una reformulación de relaciones de poder existentes entre varones y mujeres" (Chacón, 2002).

Chakana: es una síntesis de la cosmovisión de la región 
andina. Los Cañaris tienen una chakana especial redonda, se distribuye en cuatro sitios con inscripciones de pumas, en el medio hay un círculo (puerta para penetrar al Uku Pacha), a cada lado se colocan: agua, frutos y productos de la tierra, fuego sagrado y plantas que representan el buen aire.

Luna: Considerada como una de las más importantes de sus deidades ya que representa el cambio y la evolución, tenían altares para los rituales, y principalmente para el registro de siembras y cosechas.

Sol: la deidad más antigua de la humanidad, considerado un dios muy importante para ellos, la fiesta del sol "Inti Raymi" es una celebración que se desarrolla para dar gracias a este y a la Pacha Mama por todos los frutos brindados. En esta obra el autor también señala que cada 25 de diciembre se da el nacimiento del sol y para que esto suceda las estrellas se alinean hacia él (Qhapaq, 2012).

Por otro lado, se observó que esta civilización utilizó rasgos muy significativos con uso de elementos geométricos muy importantes sobre los fundamentos del diseño como:

Retículas: "Las retículas son líneas verticales, y horizontales, parejamente espaciadas, que se cruzan entre sí, lo que resulta en una cantidad de subdivisiones cuadradas de igual medida" (Wong, 2014, p.61).

Fig. 1. Retícula.

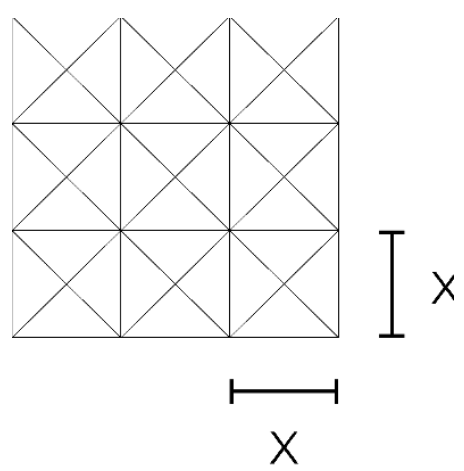

Fuente: Castro, Lema y Nievecela (2020).

La retícula es una herramienta que facilita una mejor evolución en el diseño y a través de su estructura permite lograr mayor equilibrio en las composiciones, ordenando de una mejor manera los textos e imágenes.
Simetría: "Las figuras simétricas son figuras regulares cuyas mitades izquierda y derecha se pueden obtener por reflexión en el espejo. Una recta invisible, un eje divide la figura en dos partes iguales" (Wong, 2014, p.170).

Fig. 2. Simetría.

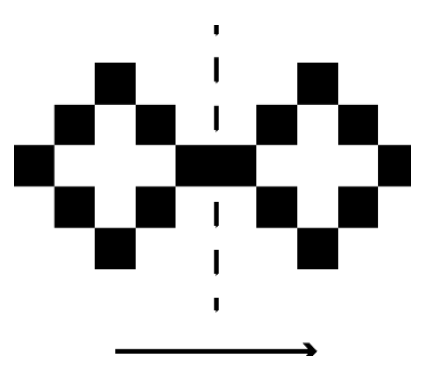

Fuente: Castro, Lema y Nievecela (2020).

La simetría ofrece un perfecto equilibrio visual ya que permite colocar los elementos que conforman la composición gráfica de todo diseño a la misma altura tanto en un lado como el otro, posee la misma selección cromática, las mismas texturas, y en general, semejan un espejo cuando se coloca cualquier objeto frente a él.

No es un requisito obligado del diseño, al contrario, el no usarla también permite ser atractivo con el producto, permitiendo la posibilidad de romper con la monotonía visual cuando se la utiliza. El todo caso, la simetría representa una más de las posibilidades del diseño y permite brindar imágenes sólidas, formales y con el sentido de orden que ciertos trabajos necesitan.

La Cultura Cañari usa la simetría en la composición de sus gráficos decorativos, tanto en cerámica como textiles, está presente en la Fase Narrío, Tacalshapa y Cashaloma. Dentro de la operatoria del diseño, es una de las razones principales por la que fue tomada en cuenta para la realización de este proyecto.

Radiación: "Los módulos repetidos o las subdivisiones estructurales que giran regularmente alrededor de un centro común producen un efecto de radiación” (Wong, 2014, p.87). 
Fig. 3. Radiación.

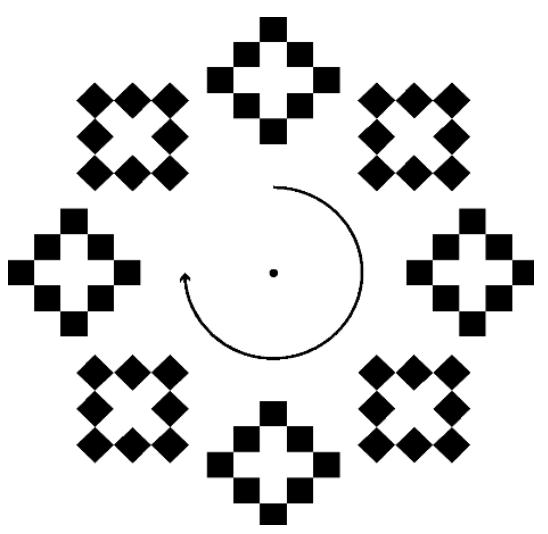

Fuente: Castro, Lema y Nievecela (2020).

Repetición: La repetición para Wong (2014), es el uso constante de la misma forma. Esta herramienta puede estar restringida a la figura o a cualquier elemento específico con variaciones en otros elementos como figura, tamaño, color y textura.

Fig. 4. Repetición.

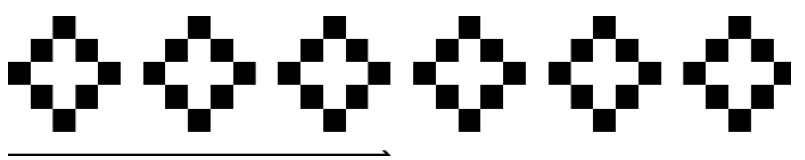

Fuente: Castro, Lema y Nievecela (2020).

Las fases Tacalshapa y Cashaloma usan la repetición en su decoración cerámica.

Traslación: Cambio de posición de una figura sin cambiar su dirección (Wong, 2014).

Fig. 5. Traslación.

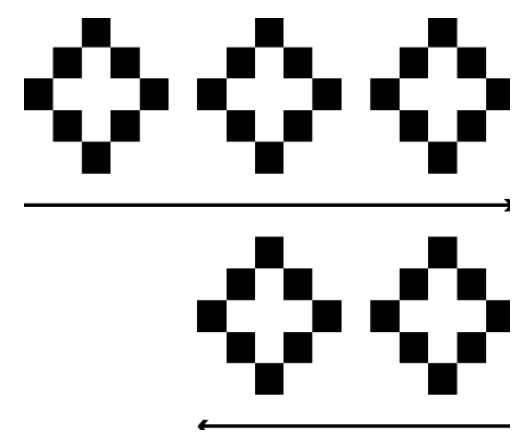

Fuente: Castro, Lema y Nievecela (2020).
La traslación de una forma hace cambiar su posición. Sin embargo, la dirección de la forma permanece invariable. La traslación es la repetición de una forma en un diseño. En las composiciones formales, los gráficos son sometidos a traslación con uso de espacios dados de manera regular. Las traslaciones pueden ser verticales, horizontales, diagonales o una combinación de ellas.

Gradación: "Se denomina gradación a la alteración sistemática de la figura, el tamaño, la posición, la dirección, la proporción o la forma” (Wong, 2014, p.212).

Fig. 6. Gradación.
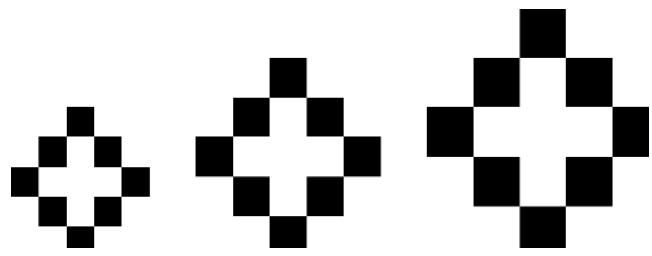

Fuente: Castro, Lema y Nievecela (2020).

Contraste: Es la combinación de diferentes intensidades o niveles de oposición, en el color, tamaño y la textura, las cuales pueden proporcionar mayor significado a una composición (Ramos, 2013).

Fig. 7. Contraste.
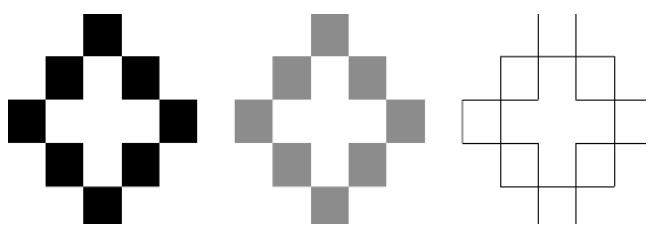

Fuente: Castro, Lema y Nievecela (2020).

Según Dondis (1989): “El contraste más efectivo se obtiene combinando los diferentes tonos, el contraste creado entre dos colores será mayor cuanto más alejados se encuentren del círculo cromático" (p.63).

La Cultura Cañari es muy rica en la expresión de formas, debido a la infinidad de elementos en cuanto a diseño se refiere, inspirados en la naturaleza realizaban abstracciones con una marcada importancia tomando como énfasis elementos como la luna, el sol, etc., que a la vez se convirtieron en sus deidades tal como se explicó 
anteriormente, además usa formas geométricas como cuadrados, espirales, círculos entre otros.

Relación semiótica: Mediante el análisis y el estudio semiológico realizado se midió el grado de relación entre los conceptos plasmados de manera intrínseca en los objetos para mostrar y mantener los criterios con detalles innovadores, de una manera contemporánea, a los elementos representados mediante la aplicación del diseño.

Fig. 8. Vaso antropomorfo geométrico pintado.

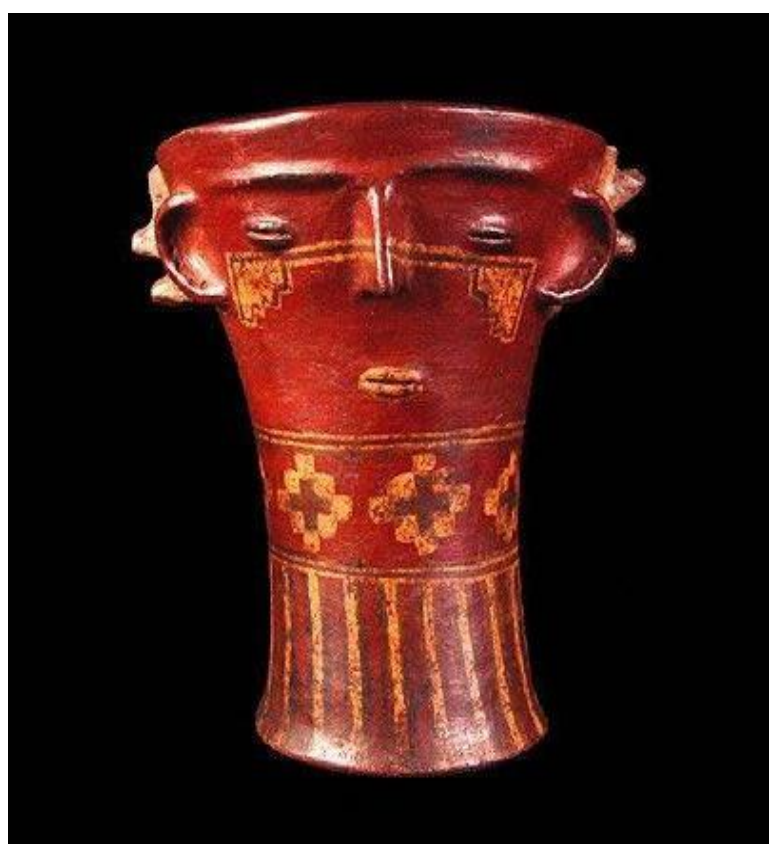

Fuente: Avilés, Pino, E. (s/f) Confederación Cañari. Enciclopedia del Ecuador. Recuperado de: http://www.enciclopediadelecuador.com/historia-delecuador/confederacion-canari/

Durante la etapa de abstracción morfológica, a partir de la selección de los elementos más significativos, se realizaron los bocetos iniciales utilizando una retícula modular para la geometrización de las figuras. Luego, con el uso de los fundamentos de diseño antes mencionados, se realizó la construcción de las propuestas para la obtención de estas.

Fig. 9. Interpretación y representación.

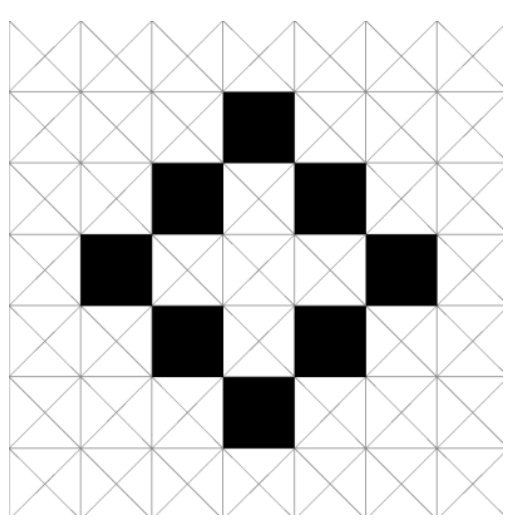

Fuente: Castro, Lema y Nievecela (2020).

\section{EXPERIMENTACIÓN}

Los vestigios Cañaris poseen una gran cantidad de recursos creativos, permitiendo establecer una amplia fuente de modelos en donde se pueden implementar constantes y variables para la generación de nuevas propuestas. Por otro lado, es importante mencionar a la parte simbólica como identificador propio, ya que permite potenciar el grado de significado dentro de cada elemento desde el punto de vista de su cosmovisión.

Al hablar de diseño se puede decir que el diseño es un proceso de creación visual con un propósito. A diferencia de la pintura y la escultura, que son la realización de las visiones personales y los sueños de un artista, el diseño cubre exigencias prácticas. Una unidad de diseño gráfico debe ser colocada frente a los ojos del público y transportar un mensaje prefijado. Un producto industrial debe cubrir las necesidades de un consumidor (Wong, 2014, p.41).

El diseño usa, en su gran mayoría, un sistema de identidad gráfica siendo clave el uso de variables desde soportes, formatos, hasta piezas con diferentes necesidades; por otro lado, es también relevante las constantes del sistema, puesto que nos ayudará a llevar a cabo varias propuestas del proyecto sin agotar sus recursos y a la vez crear una riqueza visual.

Cuando se habla de variables y constantes se dice que existen 
algunos elementos gráficos que no siempre aparecen o aparecen en diferentes proporciones, con esto se puede anotar que, depende de las decisiones del diseñador al momento de proponer la obra, y el sistema puede tener su propio lenguaje muy ligado al código particular al cual representa.

Un sistema gráfico puede variar de tipología según el grado de complejidad que presente sus características y la flexibilidad de este, además se debe indicar que también existen los sistemas conceptuales, estos últimos se relacionan a la parte connotativa en donde el significado del sistema es el núcleo, en ella puede coexistir diferentes elementos gráficos pero el concepto sigue siendo la base de la propuesta.
También existen sistemas mixtos donde las constantes y variables se encuentran presentes desde el punto de vista formal como conceptual dando la facilidad de incorporar los elementos externos que den más dinamismo y diferentes puntos de vista a la propuesta. El manual de representación de formas sígnicas de la Cultura Cañari expone los principios básicos del diseño gráfico considerados en el análisis e interpretación de los vestigios de dicha civilización. Adquiere relevancia fundamental y estratégica para la comunicación del proyecto, mediante una equilibrada combinación de antecedentes históricos, teoría y práctica del diseño. De esta manera, el lector encontrará en estas páginas información relevante de la metodología propuesta que se organiza en 5 puntos:

\section{ANÁlISIS DE FORMAS}

Fig. 10. Inti Raymi, la gran fiesta del sol y la cosecha.

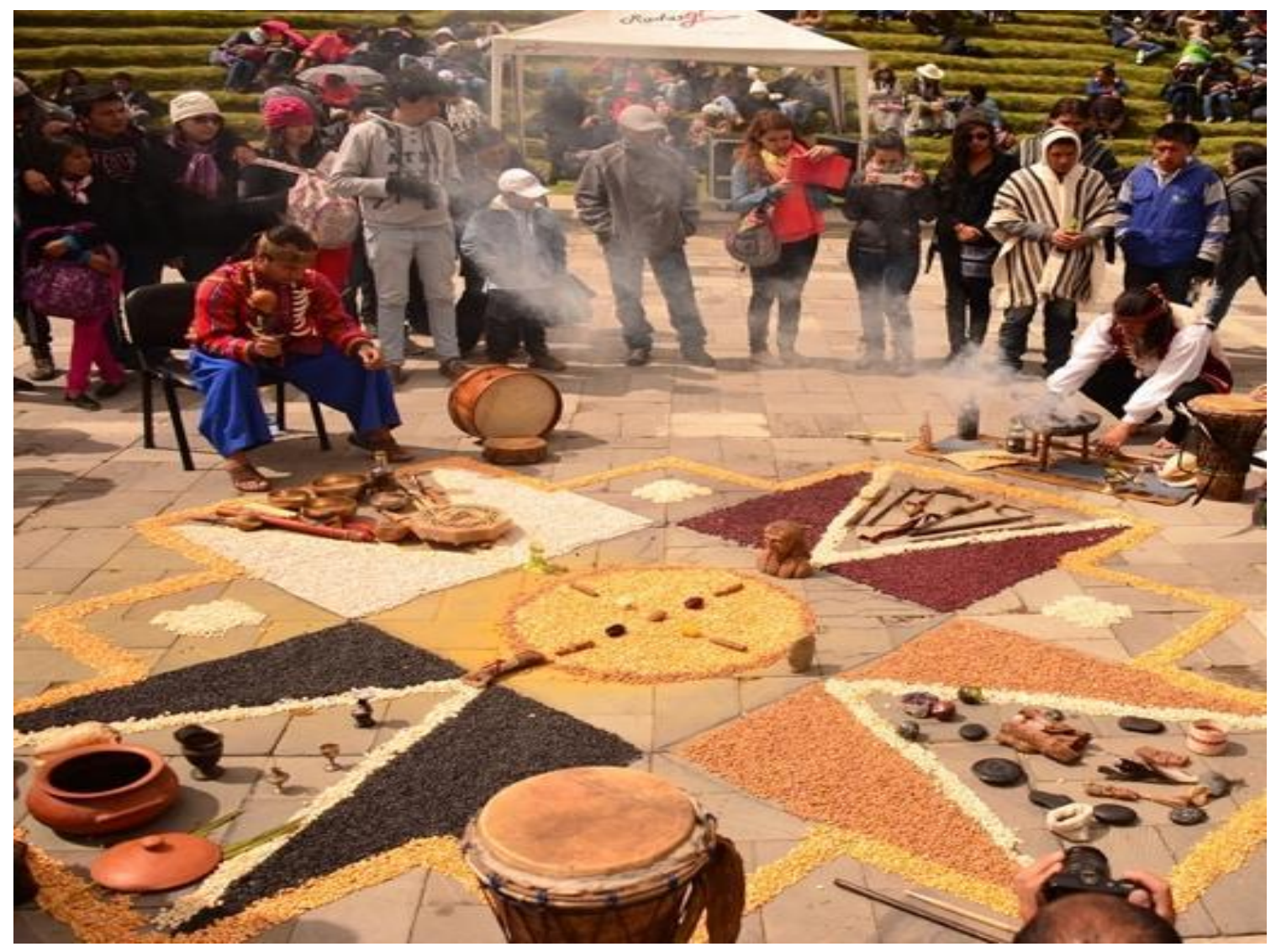

Fuente: Ministerio de Turismo (2016). Inti Raymi, la gran fiesta del sol y la cosecha. Recuperado de https://www.turismo.gob.ec/inti-raymi-la-gran-fiesta-del-sol-y-la-cosechal. 


\section{GEOMETRIZACIÓN}

Fig. 11. Retícula y representación de elemento simbólico.

Fig. 13. Familia tipográfica.

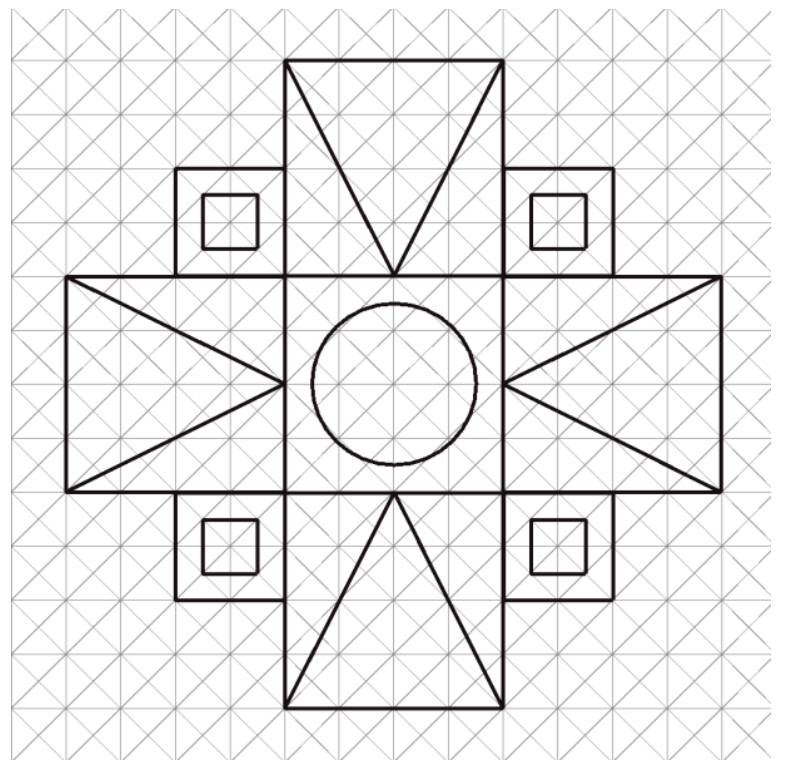

Fuente: Castro, Lema y Nievecela (2020).

\section{CROMÁTICA Y TIPOGRAFÍA}

Fig. 12. Vestimenta tradicional Cañari.

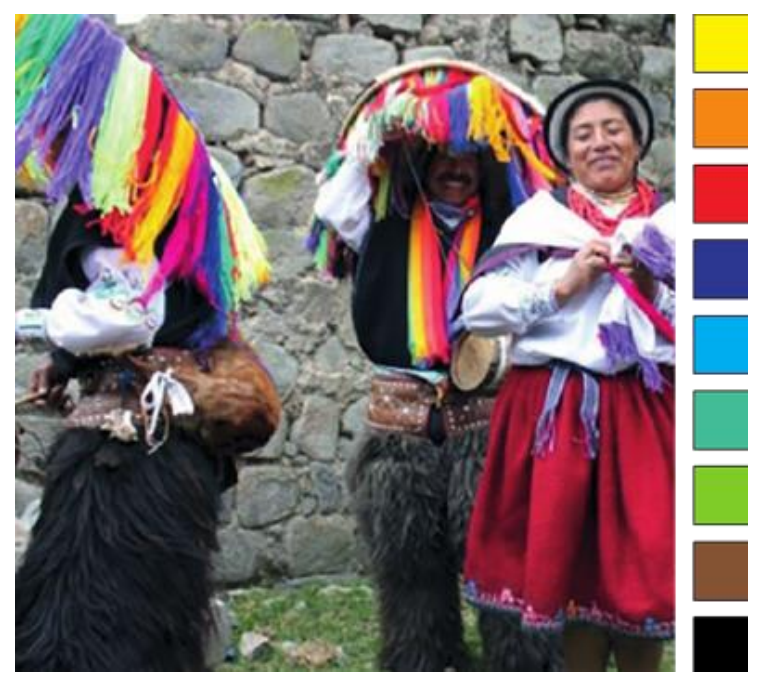

Fuente: Tomado de Avilés, Pino, E. (s/f) Confederación Cañari. Enciclopedia del Ecuador. Recuperado de: http://www.enciclopediadelecuador.com/historia-delecuador/confederacion-canari/ abcdefghijklm nopgrstuvwxyz

\section{ABCDEFCHIJKLM}

NOPQRSTUVWXYZ

0123456789

\section{$+. *=\$ \% \& \# @()[]\{\}$ ?}

Fuente: Castro, Lema y Nievecela (2020).

\section{COMPOSICIÓN}

Fig. 14. Repetición, rotación y escala.

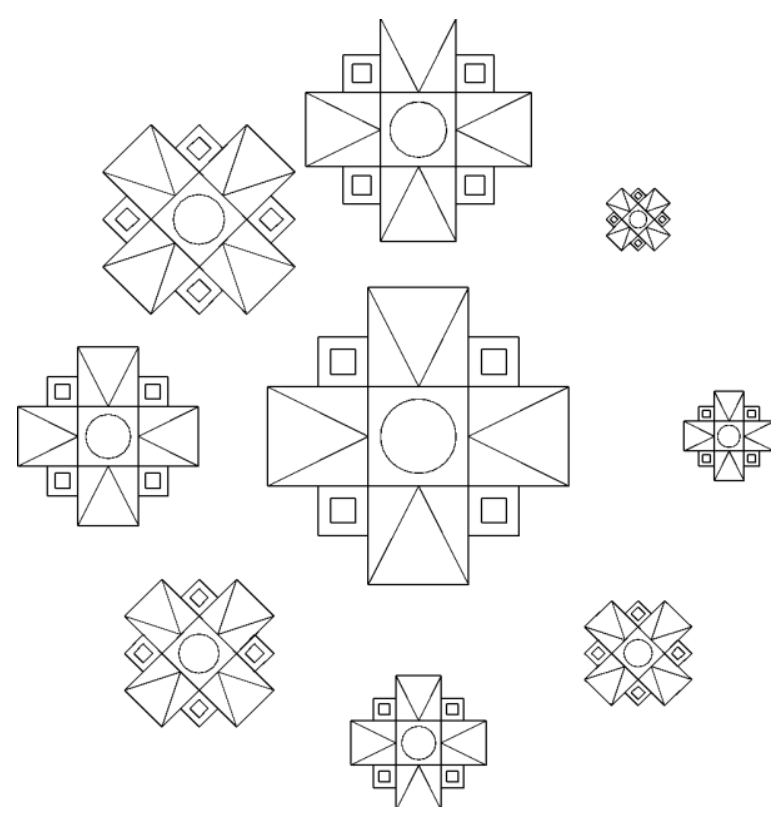

Fuente: Castro, Lema y Nievecela (2020). 


\section{SIMULACIÓN}

Fig. 15. Simulación de diseño aplicado a bolsa ecológica.

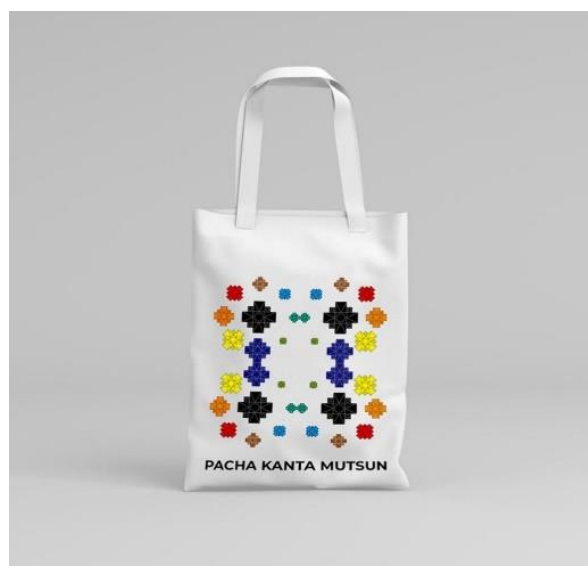

Fuente: Castro, Lema y Nievecela (2020).

\section{CONCLUSIÓN}

El proceso de diseño creativo tiene varias metodologías, esta propuesta ha tratado de generar, mediante su aplicación, un sistema de elementos gráficos que han sido formados a partir de figuras de la Cultura Cañari, en donde cada uno de estos gráficos pudieron ser la base para la obtención de nuevas formas, en las mismas con el uso de los fundamentos del diseño y su aplicación han permitido la obtención de rediseños contemporáneos con las cuales se ha podido fabricar, en este caso, objetos de uso cotidiano.

El objetivo del documento es evidenciar la toma de decisiones en cuanto a diseño, difundir la riqueza gráfica de la Cultura Cañari y la funcionalidad en la aplicación sobre productos tangibles, en este caso, bolsas ecológicas, donde están presentes elementos simbólicos, por ello la metodología propuesta obedece a conceptos básicos del diseño para una aplicación refinada a la gráfica precolombina. 


\section{REFERENCIAS BIBLIOGRÁFICAS}

Avilés, Pino, E. (s/f) Confederación Cañari. Enciclopedia del Ecuador. Recuperado de: http://www.enciclopediadelecuador.com/hist oria-del-ecuador/confederacion-canari/

Basantes, A. V., Naranjo, M. E., Gallegos, M. C., \& Benítez, N. M. (2017). Los dispositivos móviles en el proceso de aprendizaje de la Facultad de Educación Ciencia y Tecnología de la Universidad Técnica del Norte de Ecuador. Formación universitaria, 10(2), 79-88.

Google Scholar

Chacón, J. (2002). Plaza donde se origina la gente Cañari Paucarbamba. Matriz Cañari de Cuenca.

Dondis, D. A. (1992). La sintaxis de la imagen. Introducción al alfabeto visual. Ed. Gustavo Gili, Barcelona.

Google Scholar

Eco, U. (2000). Tratado de semiótica general. Lumen.

Google Scholar

Estrada, E. (1958). Las culturas pre-clásicas, formativas o arcaicas del Ecuador. Museo Victor Emilio Estrada. Guayaquil.

Google Scholar

Garzón, M. (2012). Cañaris. "Cañaris del sur del Ecuador y Mitmaq Canaris del Perú”. Cañar: Gráficas Hernández.

Google Scholar

Martín-Barbero, J. (2002). Medios y culturas en el espacio latinoamericano. IBEROAMERICANA. América Latina - España - Portugal, 2 (6), 89-106. DOI: http://dx.doi.org/10.18441/ibam.2.2002.6.89-106

Google Scholar
Ministerio de Turismo (2016). Inti Raymi, la gran fiesta del sol y la cosecha. Recuperado de https://www.turismo.gob.ec/inti-raymi-la-granfiesta-del-sol-y-la-cosechal

Qhapaq, J. A. (2012). Cosmovisión andina. Revista Inka Pachaqaway Primera. Cuenca.

Ramos, M.E.S., y García, C.D.B. (2019). Los principios fundamentales del diseño. Insigne Visual-Revista del Colegio de Diseño Gráfico-BUAP, 2(22).

\section{Google Scholar}

Wong, W. (2014). Wucius Wong-Fundamentos del Diseño. Barcelona: Gilli.

Google Scholar 